\title{
Teaching System on Theory and Practice for Tourism Management Major of Middle Vocational Undergraduate
}

\author{
Hongyan Liu \\ College of Finance and Trade, Bohai University, Jinzhou, 121013, China
}

47203209@qq.com

\begin{abstract}
Keywords: middle vocational undergraduate; tourism management major; personnel training specification; theoretical teaching; practical teaching
\end{abstract}

\begin{abstract}
Theoretical teaching and practice teaching are two basic forms of professional teaching, both of them are the dialectical unification's relations. This article is in order to improve the quality of secondary vocational undergraduate tourism management talents training. First of all, the research of quality structure, ability structure and knowledge structure of professional personnel training specification; Then, research the basic theory, professional theory and the theory of the three modules such as general theory teaching system; Finally, research by the quality extension, basic skills, professional skills, professional ability, practice and innovation mode of modules such as practice teaching system. Used in this paper, the research results, to produce more there are both system of theoretical knowledge and practical ability, satisfy the need of society, a senior tourism professional management personnel.
\end{abstract}

\section{Introduction}

Middle vocational undergraduate tourism management professional training goal is to meet the needs of the socialist market economic construction, beauty, intelligence and physique full scale development, management, economy, tourism and other solid basis of knowledge, strong practical ability and innovation spirit, can in enterprises, public institutions and government departments engaged in tourism management and teaching work of moral, intellectual, physical, all-round development of the applied senior specialized talents. It's embodies the following obvious characteristics: the talent cultivating target of talent training, occupational knowledge and ability, talent types of applicability, employment direction at the grass-roots level and the diversity of training means, etc.

Theoretical teaching and practice teaching are two basic forms of professional teaching, both of them are the dialectical unification's relations [1]. Practice teaching based on system theory teaching, should be carried out in under the guidance of professional theory; Theory teaching should serve for practice teaching, to cultivate the students' practice ability; Through teaching practice, make up for a lack of perceptual knowledge in the process of theoretical teaching, promote the student to the theory of teaching knowledge understanding, and in the process of practice teaching, to solve the theoretical teaching in hasn't been able to solve some specific problems; Through teaching practice, to examine the effects of theory teaching and even the whole professional teaching quality, and to enrich the content of theoretical teaching.

In order to improve the quality of middle vocational undergraduate tourism management talents, this paper studies the theory teaching and practice teaching the integration of teaching system, focuses on systemic theory teaching, practice teaching scheme is feasible, both close cooperation, mutual penetration, to produce more there are both system of theoretical knowledge and practical ability, satisfy the need of society, a senior tourism management talents and professional service.

\section{Personnel Training Specification}

Personnel training specification school to cultivate the talented person quality standard regulation, refers to the educatees should reach comprehensive quality. Specifications of colleges and universities are institutions of higher learning in various professional training goal refinements, is 
the specification requirements for the graduate training quality, is the teaching plan and teaching outline, teaching organization, check and evaluate the quality of education the basis, the direction of the professional personnel training problems. Tailored to each major education training objectives of comprehensive quality requirements, is in the direction of professional personnel training and to achieve the goal of a general description, and the professional talents in knowledge and ability to achieve the basic requirement of [2].

Education quality standards can be divided into two levels, one is the basic quality requirements of general, other one is specific eligibility criteria. The first level is referring to national unity of undergraduate professional personnel training specification requirements; At the second level is referring to institutions of higher learning needs to adapt to the specifications of the diversity of society for talents of all kinds of personnel training specification. Personnel training specification, therefore, has two characteristics, namely the unity and diversity. Middle vocational undergraduate tourism management professional personnel training specification as shown in Fig. 1.

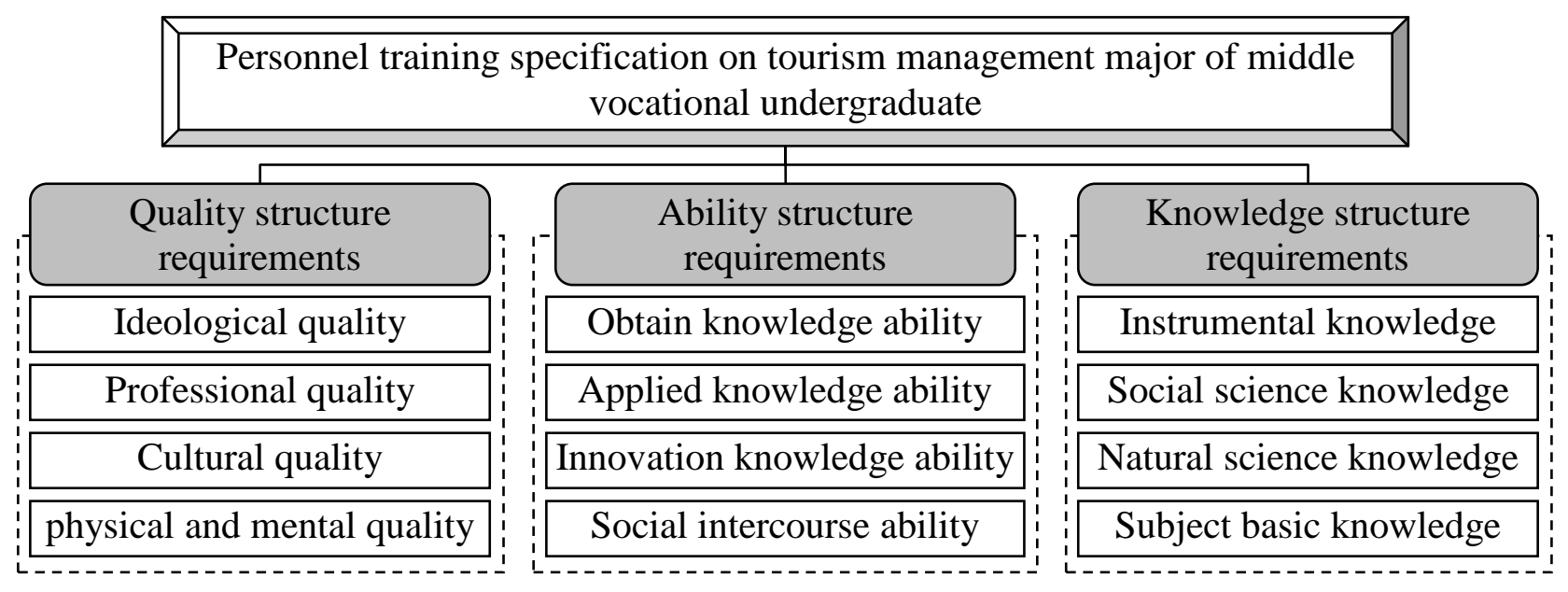

Fig. 1. Personnel training specification on tourism management major of middle vocational undergraduate

Quality structure requirements [3]: (1) Ideological quality. Form a good style of study, with a hard practical, good at cooperation and innovation of scientific spirit, have good ideological and moral cultivation and the psychological quality; (2) Specialized quality. Master the basic theory and methods, such as management, economics and tourism, understand the laws of tourism industry and the leisure economy, has the hotel operation and management, convention and exhibition management, leisure and sports management theory knowledge and basic skills; (3) Cultural quality. Has a good humanities, arts, culture and language expression ability, take an active part in social practice, to China's outstanding traditional culture and thought has certain understanding; (4) Physical and mental qualities. To master the basic skills of scientific exercise, to the provisions of the state of college students' sports qualified standard, physical and mental health.

Ability structure requirements: (1) Obtain knowledge ability. Independent access to our professional knowledge, update knowledge and application ability of knowledge. Master the basic methods of literature retrieve and grasp the tourism industry of the latest developments. It has scientific writing and the actual work ability; (2) Application of knowledge ability. Will learn the basic theory and professional knowledge to achieve mastery through a comprehensive, has found the problem, the ability to analyze and solve problems; (3) Knowledge innovation ability. Has innovation consciousness, master the thinking method of creating activities, have a certain ability of creative thinking and exploration; (4) Social intercourse ability. To properly handle the organization's ability to internal and external relations, dealing with the relation between the up and down or so.

Knowledge structure requirements: (1) Instrumental knowledge. Master the basic knowledge of the computer software and hardware knowledge, methods and tools of obtaining information through the network; (2) Social scientific knowledge. Have a certain literature, history, philosophy, art, and legal aspects of knowledge, has the good thought personal character accomplishment and 
psychological health; (3) natural science knowledge. Natural science is the study of material structure, form and motion law of nature of science. Including physics, chemistry, biology, astronomy, meteorology, geology, agriculture, medicine, mathematics, and a variety of technology science, etc; (4) the basic knowledge of discipline. To master the basic knowledge of tourism discipline, including the tourist market marketing, human resources management of tourism, tourist psychology, tourism economics, tourism enterprise financial management, economic law and regulations, professional English, etc.

\section{Theoretical Teaching System}

Theoretical teaching in classroom as a place to teachers' teaching as the main form, by listening to lectures, thinking, discussion and practice to accept the knowledge. Theory teaching is the main source of the student to obtain the basic knowledge and basic theory, teaching theory teaching system of the scientific and cultural knowledge, raises the student science image thinking and abstract thinking ability, deduction and induction ability, logical reasoning ability, the ability of analyzing and resolving problems. Some knowledge needs teachers' teaching system, to achieve a deep understanding for knowledge, and firmly grasp.

Middle vocational undergraduate course system of theory teaching principles based on "application" as the theme, moderate basic theory, knowledge and high comprehensive quality perfect seriation and modularization, the content, the theoretical system consists of three modules, as shown in Fig. 2.

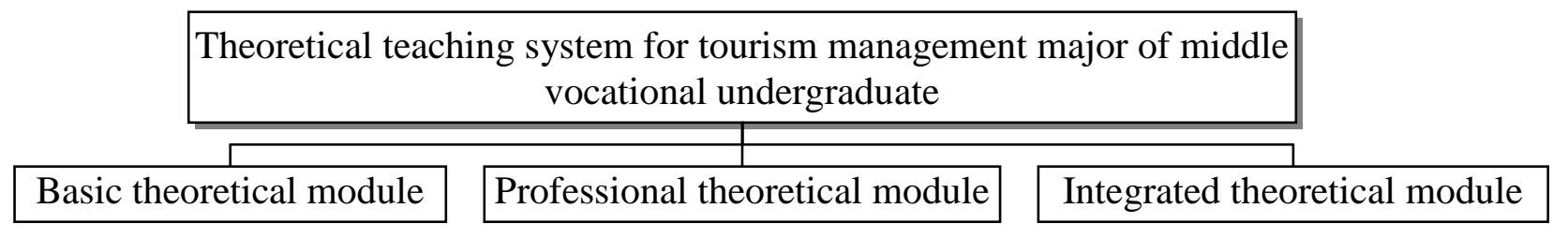

Fig. 2. Composition on theoretical teaching system for tourism management major of middle vocational undergraduate

(1) Basic theoretical module: qualified for professional post group of Basic ability and key ability of the necessary Basic knowledge and Basic theory, is a common objective laws, including natural science and social science. Such as politics, law, business writing, higher mathematics, college physics, college English, general course such as computer application basis.

(2) Professional theoretical module: qualified for Professional post (group) the Professional ability of the necessary Professional knowledge. Requirements within the scope of the professional, according to the core for integrated and practical application of professional and technical direction development, emphasized the comprehensive knowledge and practical. Tourism management courses in professional theory including tourism, tourism management, tourism policies and regulations, travel agency management, tourism geography, tourism English, hotel management, hotel catering, tourist cultures, tourist security, etc. [4].

(3) Integrated theoretical module: qualified for professional post (group) the necessary comprehensive knowledge of professional ability. Requirements around the professional ability, within the scope of the professional field of multidisciplinary integrated. Tourism management courses in comprehensive theory including the economics of tourism, tourism resources development and management, scenic spots, tourist psychology, tourist planning and management accounting, tourism marketing, tourism enterprise human resources management, financial management, project management of tourism, tourist information system, microeconomics and so on.

\section{Practical Teaching System}

Practical teaching is to consolidate theoretical knowledge and an effective way to deepen understanding of the theory, is to cultivate innovative high-quality engineering and technical 
personnel of important link, is the theory with practice, cultivate the students master the scientific method, and the ability to raise and important platform. Through teaching practice, rich and active student's scientific ideas, deepen the understanding of theoretical knowledge, cultivating students' observation of the objective world ability and analysis ability, understand the practice in the scientific theory of the status and role in the process of development.

Practical teaching system based on the basic ability training, comprehensive quality training as the core, innovative education as the main line, strive to cultivate the students' experimental ability, engineering design, professional practice ability, scientific research ability; Forging students' innovative thinking, cultivating students' innovative ability [5]. Secondary vocational practice teaching of undergraduate course system is shown in Fig. 3.

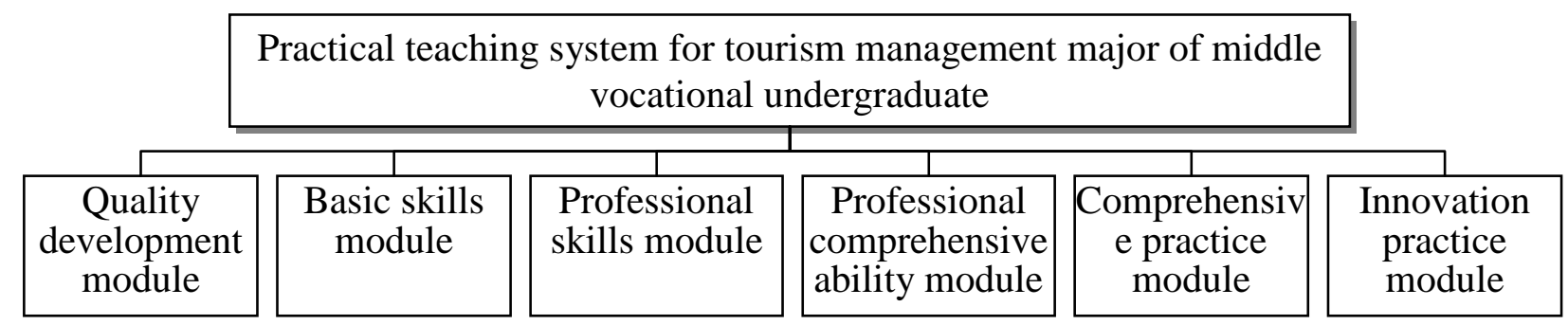

Fig. 3. Composition on practical teaching system for tourism management major of middle vocational undergraduate

(1) Quality development module: strengthen students' cognitive ability and the ability to adapt to society, to cultivate the students' comprehensive quality, good quality form helps to personal development, including military training, sports training, social practice, social survey and artistic creation.

(2) Basic skills module: to strengthen the students' mathematics, foreign language and computer application skills, train the ability of solid Basic knowledge, including basic experiments, public basic experiment, foreign language listening, speaking, reading and writing and basic computer training.

(3) Professional skills module: deepen the understanding and the understanding of Professional theory knowledge, training students' practical scientific attitude, rigorous and meticulous style of work, exercise the ability to analyze and solve problems, mainly including specialized courses experimental teaching [6].

(4) Professional comprehensive ability module: in accordance with the Professional characteristics should possess the ability to structure a Professional comprehensive ability training requirements, building Professional ability for students platform, mainly including curriculum design, training courses, graduation design (paper).

(5) Comprehensive practice module: strengthen students understanding of professional practice Comprehensive knowledge and production skills, cultivate the students' professional practice ability and the solution actual problem ability, mainly composed of cognition practice, production practice and graduation practice levels.

(6) Innovation practice module: exert students' innovative thinking and creativity, causes the student to the theory of knowledge has been consolidated and sublimation, highlight the personality development and improve the Innovation ability. Open experiment projects, including various disciplines race and academic report.

\section{Conclusion}

Tourism is the emerging of the third industry in China, has a broad development prospects. Modern tourism industry needs a large number of practical and high quality talents. At present, China's tourism industry with the market demand of talents cultivation, tourism human resources in short supply on the whole, especially applied and serious shortage of high quality talents resources [7, 8]. Tourism management professional talent training how to meet the demand of the tourism development, become the urgent need to solve the problem. The research achievements of this 
paper, to solve the middle vocational undergraduate tourism management talents training key issues, to strengthen the discipline construction, improve the training quality, and promote the development of Chinese tourism industry is of great significance in such aspects.

\section{Acknowledgement}

This work is supported by social science planning fund project of Liaoning province (L15BJY010).

\section{References}

[1] J. Chen, "On the relationship and problems of practical teaching and theoretical teaching," Journal of Hubei Correspondence University, vol. 25, no. 3, pp. 25-26, 2012.

[2] Baidu snapshot, "Excerpts of higher education research data," http://cache.baiducontent.com/c?m=9f65cb4a8c8507ed4fece7631043862c520adb332bd7a74f2f 93d55f93130c170071e3cc767e0d439191273956ee5400bdab67216b1e22b38cc8ff109be4866d7 2c8713b676d8c5663a30edfcb5154c637912afede1ef0cdf225e5adc5a7d54352ba44757197878f4 d701edd1bf3\&p=9749d21486cc41ac59b1cc2d021498\&newp=8b2a971fc5934eaf5becd4274b4 2cc231610db2151ddd14f6c\&user=baidu\&fm=sc\&query=\%C8\%CB\%B2\%C5\%C5\%E0\%D1\% F8\%B9\%E6\%B8\%F1\&qid=b2632b4b002394df\&p1=2, 2016-4-15.

[3] College of Finance and Trade, Bohai University, "Suitable training program on tourism management major ( middle vocational undergraduate)," http://210.47.176.3/page/depart/jrsmxy/news/News_Detail.asp?ID=500, 2016-4-15.

[4] L. Fang, "The optimization of the curriculum system of tourism management major from the perspective of post group," Vocational and Technical Education, vol. 37, no. 2, pp. 25-27, 2016.

[5] L. S. Zhang, "On the practice teaching reform of tourism management major in colleges and universities," Journal of Henan Institute of Education (Philosophy and Social Sciences), vol. 35, no. 5, pp. 114-117, 2016.

[6] C. L. Wang. Kang, "Thoughts on the construction of tourism management specialty in higher vocational education," Modern Business Trade Industry, vol. 29, no. 4, pp. 190-191, 2016.

[7] F. Zhu, "The Present Situation and Countermeasure of the Undergraduate Education of Tourism Management Specialized in Higher Education College," Journal of Chengdu University (Educational Sciences Edition), vol. 22, no. 7, pp. 39-42, 2008.

[8] F. Liu, "Research on current situation and countermeasures of undergraduate education in tourism management specialty in colleges and universities," Manager' Journal, vol. 31, no. 1, pp. 385, 2015. 